\title{
Musicae Scientiae
}

http://msx.sagepub.com/

Is there a peak in popular music preference at a certain song-specific age? A replication of Holbrook \& Schindler's 1989 study

Jan Hemming

Musicae Scientiae 2013 17: 293

DOI: $10.1177 / 1029864913493800$

The online version of this article can be found at:

http://msx.sagepub.com/content/17/3/293

Published by:

(SAGE

http://www.sagepublications.com

On behalf of:

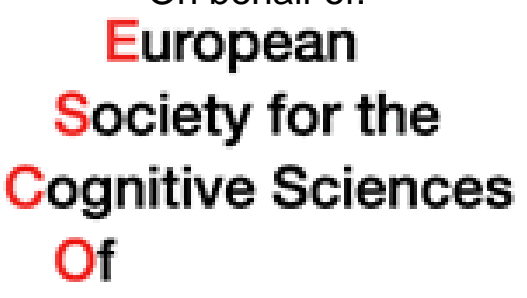

\section{Music}

European Society for the Cognitive Sciences of Music

Additional services and information for Musicae Scientiae can be found at:

Email Alerts: http://msx.sagepub.com/cgi/alerts

Subscriptions: http://msx.sagepub.com/subscriptions

Reprints: http://www.sagepub.com/journalsReprints.nav

Permissions: http://www.sagepub.com/journalsPermissions.nav

Citations: http://msx.sagepub.com/content/17/3/293.refs.html

>> Version of Record - Sep 4, 2013

What is This? 


\title{
Is there a peak in popular music preference at a certain song-specific age? A replication of Holbrook \& Schindler's I 989 study
}

Musicae Scientiae 17(3) 293-304 (C) The Author(s) 2013

Reprints and permissions: sagepub.co.uk/journalsPermissions.nav DOI: $10.1177 / 10298649 / 3493800$ msx.sagepub.com @SAGE

\section{Jan Hemming}

University of Kassel, Germany

\begin{abstract}
This is a replication and further interpretation of Holbrook and Schindler's study "Some Exploratory Findings on the Development of Musical Tastes" from 1989. Holbrook and Schindler's investigation has been widely acknowledged in music psychology as well as in consumer research and has helped further the assumption that people generally cling to music and other cultural objects they get to know in late adolescence/early adulthood. In the current replication study, a peak in musical preference across songspecific age could be confirmed, but it shifted from 23.47 years in the original study to 17.36 years in the replication. This could possibly be explained by subjects' earlier exposure to music and increased media familiarity. However, it could be shown that preferences at these peaks do not significantly differ from preferences at other ages. Also, the inverted U-shaped curve featured in the original study could not be observed among individuals' ratings, which tend to prefer music which is either gradually older or else gradually younger than themselves. The U-shaped curve seems to emerge as an artefact of combining two types of rather linear data into one chart. In fact, no empirical evidence remains to sustain the overall cultural assumption which has its basis in Holbrook and Schindler's study. It might still be valid, as evidenced by people having experienced the generation effect individually, but alternative research strategies will have to be developed to provide its empirical confirmation.
\end{abstract}

\section{Keywords}

consumer research, generation effect, music preference, replication, U-shaped relationship

\section{Background}

Research on the development of musical tastes has seen significant advances since the publication of Holbrook and Schindler's original study, "Some Exploratory Findings on the Development of Musical Tastes" in 1989. The title itself implies a call for extension and replication of the findings, which forms the core of the current article. It is common in music psychology to define "musical preferences" as the subjective degree of currently liking a certain piece of music, whereas "musical taste" refers to long-term preferences for certain musical

\section{Corresponding Author:}

Jan Hemming, Institute for Music, University of Kassel, Moenchebergstr. I, 34109 Kassel, Germany.

Email: jan.hemming@uni-kassel.de 
styles (Gembris, 2002, p. 496; North, 2010). Numerous studies have shown that music preferences are age-dependent - whereas the youth prefers Pop, Rock or Hip-Hop, older people more frequently turn to country music (or Schlager in Germany), jazz or classical music (Behne, 1997; Gembris \& Hemming, 2005; Siivola, Obert, LeBlanc, \& Sims, 1996). Holbrook and Schindler's original study has been influential in demonstrating that what appears as agedependency on the surface is actually superimposed by generation-effects. Accordingly, individual musical tastes don't shift as much in the course of a lifetime as the age-dependency suggests; instead, we seem to cling to the music we prefer in late adolescence/early adulthood. Holbrook and Schindler calculated a maximum of this effect for the "song-specific age" of 23.47 years. This value has been widely acknowledged in consumer research (Web of Knowledge currently lists 60 citations in business and management) and in music psychology ( 26 entries; for an overview: North, 2010; Schäfer \& Sedlmeier, 2010) as it provides a powerful cultural explanation for an effect many people have experienced individually. However, what the authors labelled as a "parsimonious inductive proposition" (p. 119) has not been updated or verified since 1989.

The original study was based on a sample of $N=108$ and "consisted primarily of male and female members of a local rugby club, a woman's church group, and a parent-teacher association" (Holbrook \& Schindler, 1989, p. 120). While the ages of the individuals covered a wide range from 16 to 86 years $(M=54.3)$, the sample was likely to be clumped and quite small compared to nowadays' requirements. However, this limitation never seemed to be crucial as the number of value pairs could be considerably extended in a clever move, central for the original study (which actually saved the researchers from having to set up an extensive longitudinal design): each of the subjects rated 28 music examples in the length of 30 seconds taken out of the top 10 of Billboard's annual music charts in a two year-interval from 19321986. Next, individual song-specific ages were calculated by subtracting the year of birth from the year of the release of the song. This resulted in 125 song-specific ages ranging from -39 (the oldest title tested was released 39 years before the birth of the youngest subject) to 85 (the oldest subject was 85 years old in the year of the release of the newest title). These could be paired to $108 \times 28=3024$ rating values (minus one missing value). Having actually collected musical preferences, the researchers were thus able to say something about the development of musical tastes.

The standardized and aggregated ratings across song-specific ages are displayed in Figure 1. Its inverted U-shaped curve shows the before-mentioned peak of individual musical preferences at the age of 23.47 and a remarkable decline in preference for music one gets to know at earlier or later stages in life.

This value has somewhat become a standard within research on musical preferences, also because it seems plausible and often matches individual experiences. However, since longitudinal designs can hardly be realized, Holbrook and Schindler's study is still the only one available to even provide a distinct value. It therefore seemed to be time for a replication in a different Western country about a quarter of a century later.

\section{Aims and method}

The present study aims at a replication and further interpretation of Holbrook and Schindler's (1989) original findings. As in the original, the current study features a unifactorial design with song-specific age as independent and musical preference as dependent variables. The formerly "tentative hypothesis" (p. 120) is now spelled out as follows: 


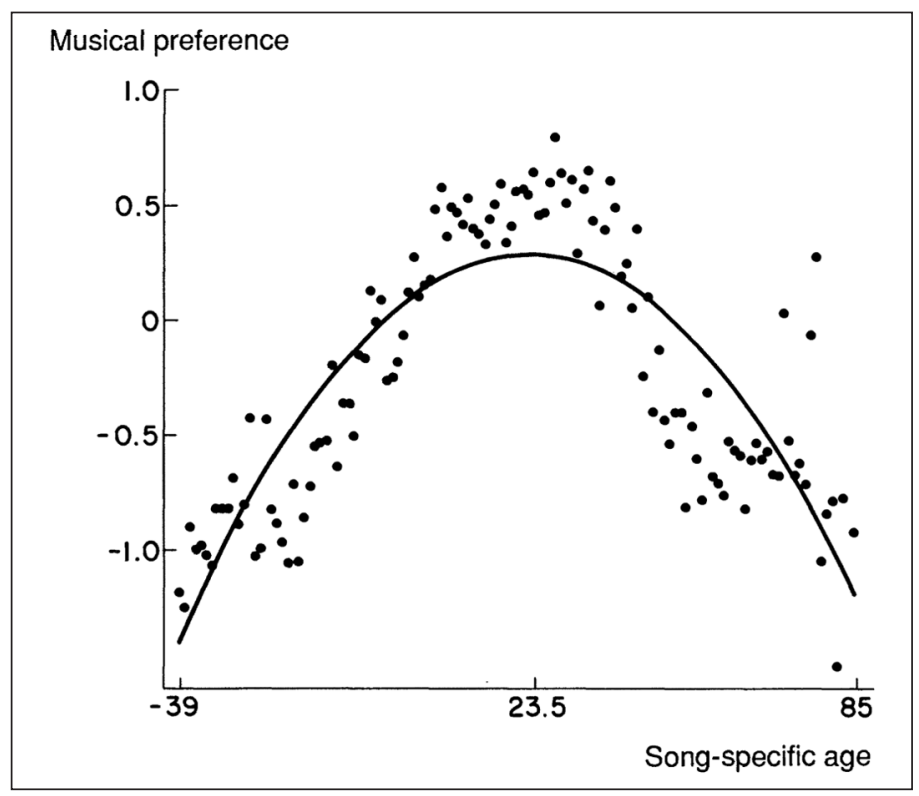

Figure I. Relationship between song-specific age and standardized preference ratings (Holbrook \& Schindler, 1989, p. 122). Reprinted with kind permission from University of Chicago Press.

H1: Taste formation for mainstream popular music occurs during a certain critical age (late adolescence/early adulthood) and remains stable throughout one's lifetime.

H1a: Pairing song-specific ages with music preference ratings standardized within subjects will result in an inverted U-shape relation. Its peak will reveal the distinct age value.

This replication addresses a much larger and more heterogeneous sample generated in and around the city of Kassel (Pop. 200,000) centrally located in Germany. Since this is a "Western society" with similar structures of music mediation and distribution, a general comparability with the original study from the Midwestern US can be assumed. The sample includes $N=473$ subjects with an age-range from 6 to $86(M=33.25, S D=17.40 ; 43.86 \%$ male, $56.14 \%$ female). Subjects were addressed in small groups by 25 students acting as researchers instructed to focus on people outside of university, with various degrees of education, musical training and covering a wide age-range.

Twenty-five music examples were drawn from Germany's annual top 10 hits from 19602008, again in two-year intervals. Table 1 displays a gradual shift from German-language titles to international pop mainstream similar to the shift from the Mills Brothers (1932) to Peter Gabriel (1986) in the original study. Again, the selection of titles was not among the top 3 of the top 10 and sometimes proved to be quite difficult. We set out using a random procedure with subsequent manual adjustments. With the technique of sampling and with growing historical awareness, popular music has entered an age of frequent covers and of self-referentiality (Dunne, 1992; Goodwin, 1988). Titles which are covers or make use of samples of older songs had to be eliminated from the music examples of the replication. However, no external advice needed to be acquired, as the author and the researchers are rooted in musicology. An emphasis was placed on the fact that typical sections of verse and chorus were included in the 30-second excerpts. The titles were placed on a CD in two different orders to eliminate sequencing and 
Table I. The musical selections from 1960-2008.

\begin{tabular}{rlll}
\hline No & Year & Title & Performer \\
\hline 1. & 1960 & Unter fremden Sternen & Freddy Quinn \\
2. & 1962 & Speedy Gonzales & Pat Boone \\
3. & 1964 & Du, Du gehst vorbei & Suzie \\
4. & 1966 & Get Off my Cloud & Rolling Stones \\
5. & 1968 & My Little Lady & Tremeloes \\
6. & 1970 & Yellow River & Christie \\
7. & 1972 & Popcorn & Hot Butter \\
8. & 1974 & Teenage Rampage & Sweet \\
9. & 1976 & Daddy Cool & Boney M \\
10. & 1978 & One For Me, One For You & La Bionda \\
11. & 1980 & D.I.S.C.O. & Ottawan \\
12. & 1982 & Der goldene Reiter & Joachim Witt \\
13. & 1984 & Two Tribes & Frankie Goes To Hollywood \\
14. & 1986 & Venus & Bananarama \\
15. & 1988 & Ye Ke Ye Ke & Mory Kante \\
16. & 1990 & I Promised Myself & Nick Kamen \\
17. & 1992 & Please Don't Go & Double You \\
18. & 1994 & It's Alright & East17 \\
19. & 1996 & They Don't Care About Us & Michael Jackson \\
20. & 1998 & Männer sind Schweine & Die Ärzte \\
21. & 2000 & Lucky & Britney Spears \\
22. & 2002 & Underneath your Clothes & Shakira \\
23. & 2004 & Perfekte Welle & Juli \\
24. & 2006 & Hips Don't Lie & Shakira Feat. Wycleff Jean \\
25. & 2008 & Bleeding Love & Leona Lewis \\
\hline & & &
\end{tabular}

associated effects. To prevent the subjects from losing orientation, a female voice announced the number of each track. As in the original study, a 10-point scale was used for the rating. Only the ends of the scale were labelled "very good"/"very bad", respectively, to obtain proper interval-scaled data.

\section{Results}

The first step in data analysis consisted of calculating the song-specific ages for all subjects. A range of 129 (from -43 to +85 ) song-specific ages could be covered with no missing values. Next, individual ratings were standardized by subtracting the mean and dividing by the standard deviation. Individual preference constellations needed to be eliminated since the ratings were to be mapped to the song-specific ages in the following step. This resulted in a transformation of originally 473 cases into $473 \times 25=11,825$ cases. Values were then aggregated for each songspecific age. It is important here to take notice that the aggregated scores for each age typically combine ratings of many subjects rating many songs. See Figure 2 for the according plot.

At first glance, an inverted U-shaped curve and an overall similarity of value-ranges to the original study can be observed. Data analysis is based on a model of multiple regression. Songspecific age forms the first (linear) independent variable, this value multiplied with itself yields 


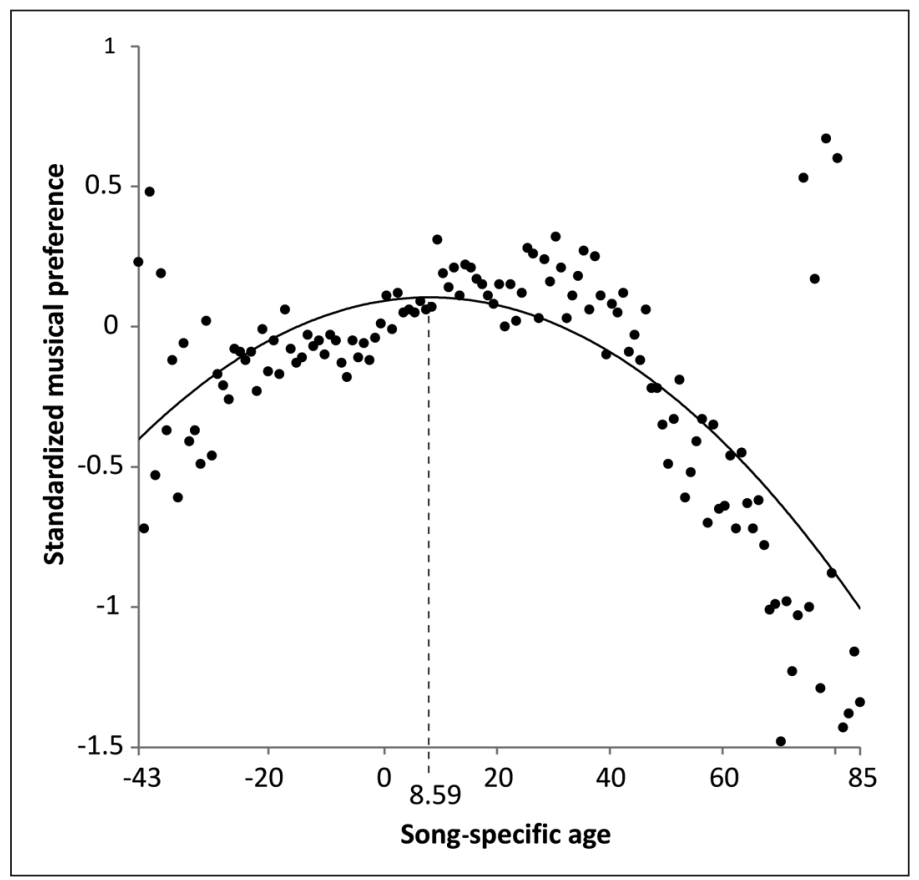

Figure 2. Relationship between song-specific age and standardized preference ratings (replication, overall aggregated data, peak: 8.59 years; $y=-0.0002 x^{2}+0.0033 x+0.0902, R^{2}=.4544$ ).

song-specific age squared which forms the second (quadratic) independent variable (actually, as hinted at on p. 122 of the original 1989 study, the variables were additionally recoded as a deviation from their own mean to eliminate collinearity). Standardized values for musical preference rating form the dependent variable to be predicted by multiple regression analysis which was carried out with SPSS for the purpose of the replication. It revealed a remarkable relation$\operatorname{ship}\left(R=.674, R^{2}=.454, F(2,126)=52.37, p<.001\right)$ which is significant for both song-specific age $(t(126)=4.95, p<.001)$ and song-specific age squared $(t(126)=-7.23, p<.001)$ ( $p$-values given in this and all subsequent calculations are equally based on unstandardized and on standardized regression coefficients). This means that the data can best be described by an equation consisting of a linear as well as of a quadratic term. The resulting equation can be found in the caption for Figure 2. However, calculating the peak by setting the first derivative of the regression equation equal to zero resulted in a value of 8.59 years. The problem which immediately arose is that absolutely no cultural explanation can be given for this finding which is also beyond the range expressed in H1 ("late adolescence/early adulthood"). While not specified in $\mathrm{H1}$, one might concede that a shift of the curve peak from the twenties to the late teens could be legitimate. Media familiarity has increased and children start using music players, etc., at younger ages, which would allow for a gradual shift of the peak to an earlier stage in life - but not to 8.59 years!

In further investigating the data, we took up Holbrook and Schindler's suggestion to look at the non-aggregated data and to draw a plot with all 11,825 value pairs. As in the original study, the disaggregated results were weaker $\left(R=.157, R^{2}=.025, F(2,11804)=149.24, p\right.$ $<.001)$ and non-significant for song-specific age $(t(11805)=-.048, p=.63)$, but significant 


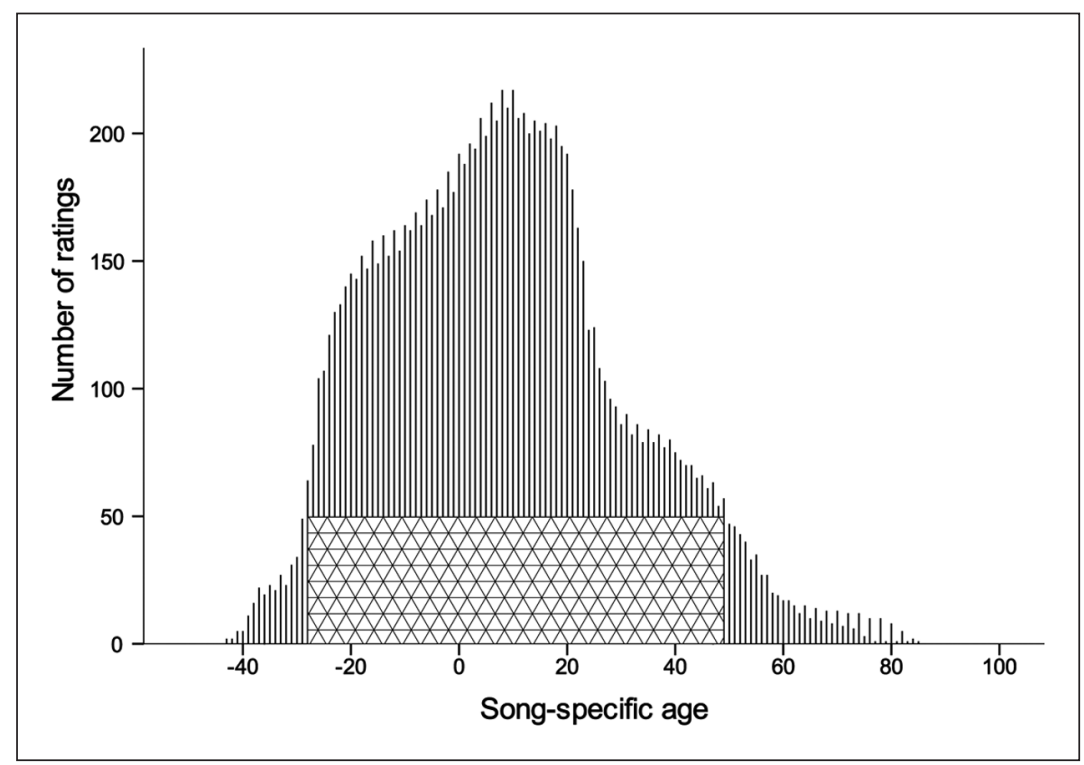

Figure 3. Number of ratings for each song-specific age and subsequent adjustment (rectangular box).

for song-specific age squared $(t(11805)=-16.22, p<.001)$. This time, the peak of the inverted U-shaped curve was at 13.47 years. How can the big difference from the aggregated data be explained? In the original study, Holbrook and Schindler had only found a slight discrepancy of the curve maxima for aggregated (23.47) and non-aggregated (23.66) data. This divergence between the original study and the replication calls for a closer look at the data structure of both investigations.

As mentioned before, the value pairs were the result of transforming both individual and song-related ratings. Depending on the age-distribution in the overall sample, the number of individual ratings (indicated in Figure 3) aggregated into one value for each song-specific age varied greatly.

While several hundred individual ratings formed the base of the aggregated values in the middle segment, they became very few at the fringes and possibly even singular at the upper and lower limits of the song-specific age range. Thus, the data points to the far left/far right both in Figure 1 (original) and Figure 2 (replication) likely arose from the very few young subjects rating the oldest title or, conversely, the very few old subjects rating the newest title. An inappropriate weight is therefore placed on these individual ratings if working with overall aggregated data. To increase objectivity, the sample was limited to aggregated values that could be based on at least 50 individual ratings (if more than 50 ratings were available, they were randomly selected). The next calculations were thus based on a reduced sample indicated by the rectangular box in Figure 3. However, this also resulted in a reduction of the song-specific age range to 78 (from -28 to 49 ) years.

Figure 4 displays the aggregated plot of all remaining value pairs including the squared regression equation (values rounded to 4 decimal places). It is still an inverted U-shape but only slightly bent down at its ends (the scale for musical preference on the y-axis was magnified compared with Figures 1 and 2). Setting the first derivative of the regression equation equal to zero revealed a peak at 17.36 years. Multiple regression analysis revealed a firm relationship 


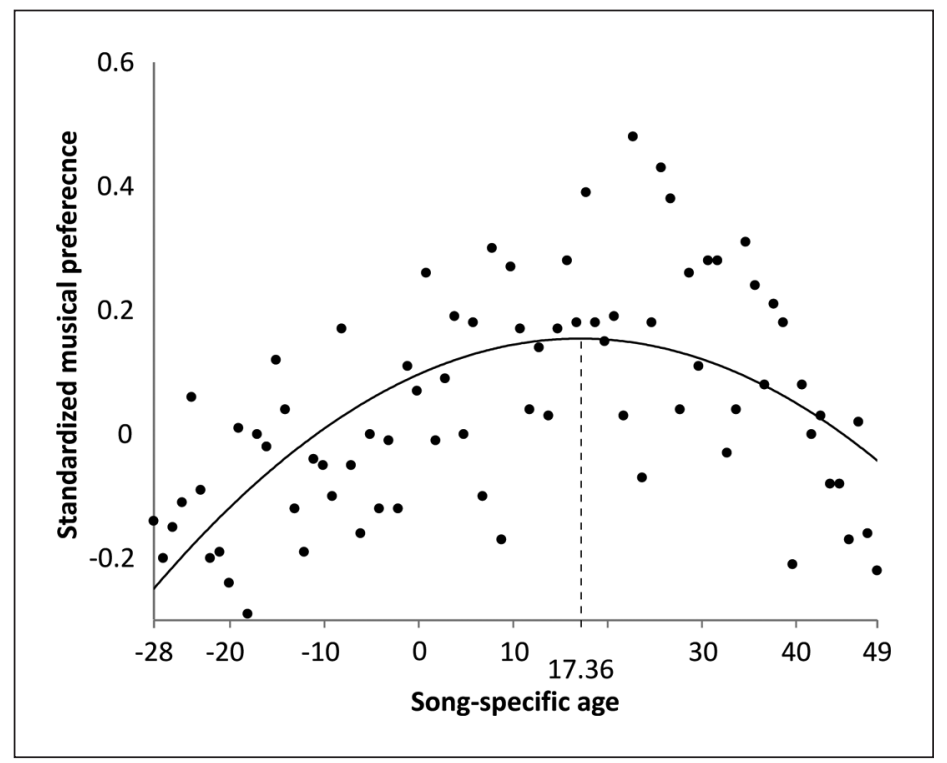

Figure 4. Relationship between song-specific age and standardized preference ratings (replication, reduced sample, aggregated data from -28 to 49 , peak: $17.36 ; y=-.0002 x^{2}+.0068 x+.0953, R^{2}=.38$ II).

$\left(R=.617, R^{2}=.381, F(2,77)=23.09, p<.001\right)$ which was highly significant for song-specific age $(t(76)=-3.22, p=.002)$ as well as for song-specific age squared $(t(76)=-5.18, p<.001)$. The procedure was subsequently repeated for non-aggregated data as displayed in Figure 5.

With the exception of the absolute offset, the regression equation for the non-aggregated data was almost identical with the one for the aggregated data. Once again, it resulted in an inverted U-shaped curve, this time peaking at a maximum of 17.11 years. Restricting the evaluation of song-specific ages to those aggregated over a fixed number of individual ratings thus proved a necessary prerequisite for comparing aggregated and non-aggregated data. It can be considered a mere coincidence that both values were only slightly different in the original study. The slight differences between aggregated and non-aggregated data observed in the replication were due to the random selection of 50 individual ratings where more were available and only became visible when taking into account complete (and not rounded) decimals. This time, multiple regression analysis again revealed a weaker relationship between the data and the curve $\left(R=.107, R^{2}=.011, F(2,3919)=22.47, p<.001\right)$. However, it was significant both for songspecific age $(t(3919)=-3.62, p<.001)$ and for song-specific age squared $(t(3919)=-16.22, p<$ $.001)$. This means that a peak in popular music preference at a certain song-specific age (17.36 years for aggregated/17.11 for non-aggregated data) does in fact exist. H1 and H1a could therefore be confirmed.

We next turned our attention to the original notion of a "highly significant relationship of popular musical preference to song-specific age” (Holbrook \& Schindler, 1989, p. 122), which implies that preference for music one gets to know at other ages significantly differs from the suggested peak at 23.47 years (or 17.36 years in the replication). To clarify this issue in the replication, song-specific ages and the corresponding ratings in the remaining range from -28 to 49 years were transformed into 16 groups, each containing the same number of ratings. The result is shown in Figure 6. Of course, the columns still roughly follow an inverted U-shaped curve. 


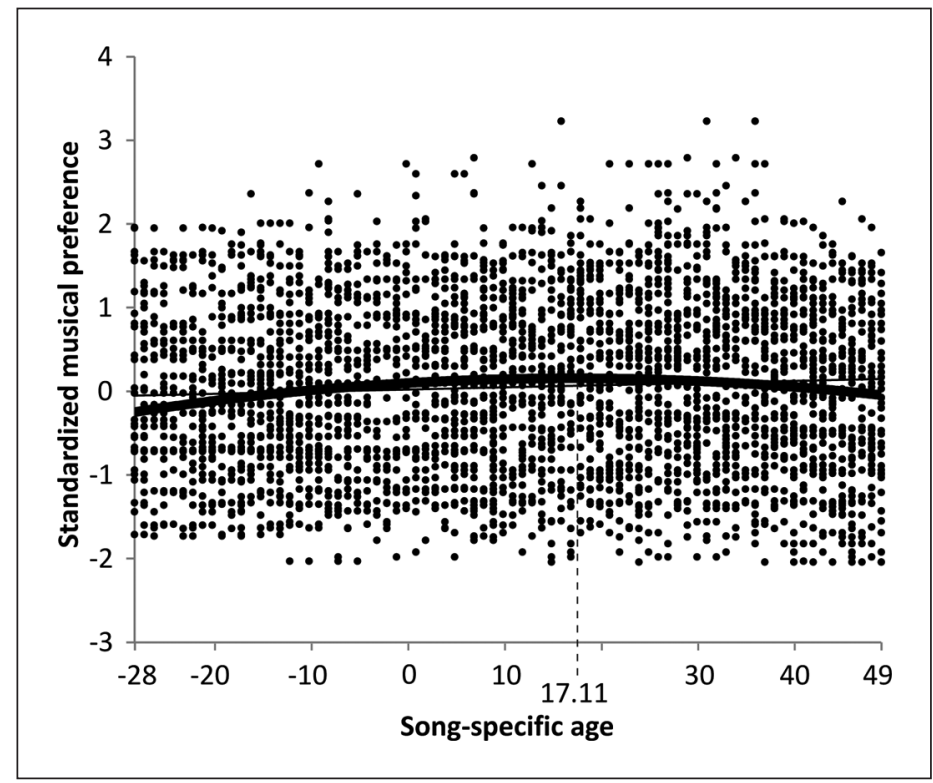

Figure 5. Relationship between song-specific age and standardized preference ratings (replication, reduced sample, non-aggregated data from -28 to 49 , peak: I $1.11 ; y=-0.0002 x^{2}+0.0068 x+0.0969, R^{2}=.0113$ )

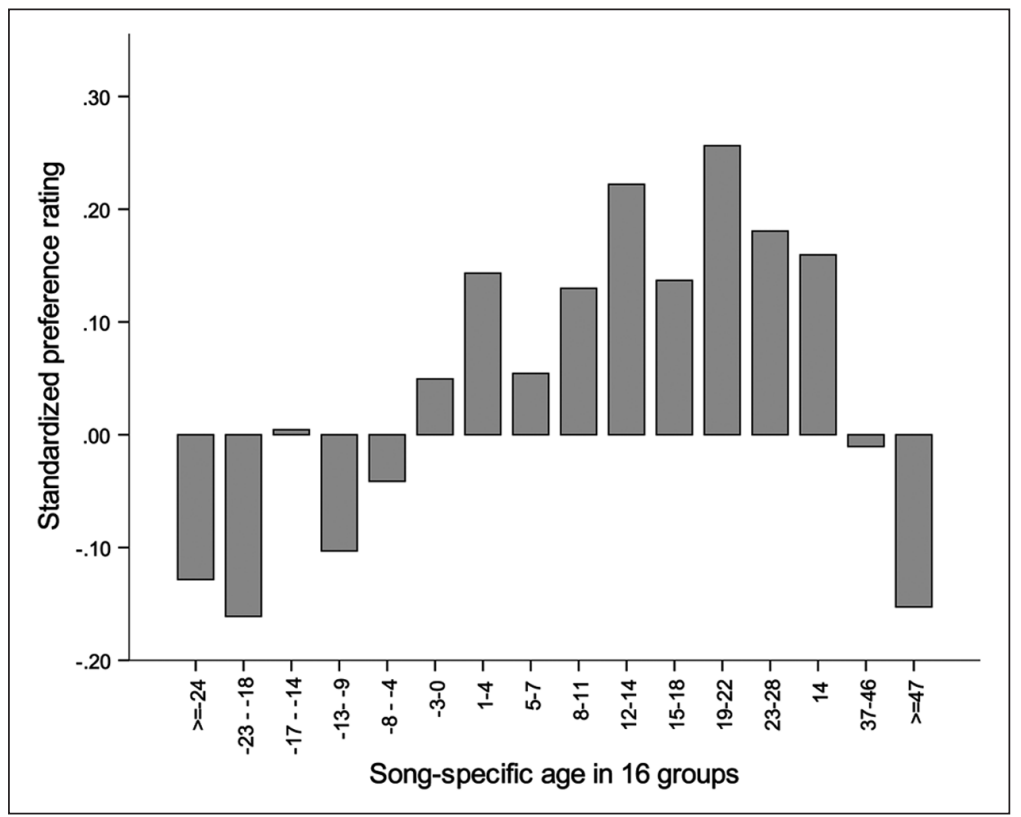

Figure 6. Standardized preference ratings in 16 groups of equal size.

Next, t-tests were calculated for all neighbouring columns (see Table 2). No significant differences could be found at all, which was partly due to the fact that average standardized group 
Table 2. Non-significant differences in standardized preference ratings between 16 neighbouring groups of equal size (values to Figure 6).

\begin{tabular}{crc}
\hline Groups & \multicolumn{1}{l}{$t$} & $p$ (2-tailed) \\
\hline $1-2$ & 0.409 & .683 \\
$2-3$ & -10.942 & .053 \\
$3-4$ & 10.268 & .206 \\
$4-5$ & -0.721 & .471 \\
$5-6$ & -0.944 & .346 \\
$6-7$ & -10.052 & .294 \\
$7-8$ & 0.975 & .330 \\
$8-9$ & -0.828 & .409 \\
$9-10$ & -0.988 & .324 \\
$10-11$ & 0.913 & .362 \\
$11-12$ & -10.233 & .219 \\
$12-13$ & 0.809 & .419 \\
$13-14$ & 0.265 & .792 \\
$14-15$ & 10.672 & .096 \\
$15-16$ & 10.507 & .133 \\
\hline
\end{tabular}

ratings were all within $\pm 0.3 S D$ or below. Had the inverted U-shaped curve been clearly pointed in the middle and steep at its sides, such differences could well have been found. Instead, the curve was so flat that no significant differences for music one gets to know at a certain age (e.g., 15-18, including the peak at 17.36 years) compared with neighbouring ages (e.g., 12-14 or 19-22) could be identified. What was found in the original study was a highly significant relationship of the data and the curve, but not a significant difference between the peak and the preference for music one gets to know at earlier or later stages in life.

In addition, since each subject rated 25 music examples from 1960-2008, it was possible to create individual curves of standardized musical preference. If Holbrook and Schindler's original conclusions were correct, one would expect to predominantly encounter individual inverted U-shaped curves with varying peaks. However, investigating the data from this perspective hardly ever yielded curves of this kind. Instead, subjects seemed to split into two groups: one with weakly increasing linear preference for newer titles, the other with remarkably increasing linear preference for older titles. This observation was clarified by determining individual correlations between standardized ratings and the age of the titles. Next, means of these values were calculated for each absolute age. The results are displayed in Figure 7.

It was clearly observable that, on average, ratings of young subjects positively correlated with the year of the release of the title. In other words, young people have strong preferences for the newest music available. At the age of 37.51 years, however, this relationship turns upside down. Ratings of older subjects negatively correlated with the year of the release of the title. The older people get, the stronger is their preference for the oldest music available. Regression analysis yielded a highly significant coefficient $(r=-.73$ while $p<.01$, Pearson, two-sided) for this overall relationship. Thus, the absolute age continued to be crucial for individual musical preference, while there remained hardly any evidence for Holbrook and Schindler's suggested generation effect.

To further clarify this issue, the data set was split into two groups: one with absolute ages up to 37 years, the other with absolute ages above 37 years. These groups were made identifiable 


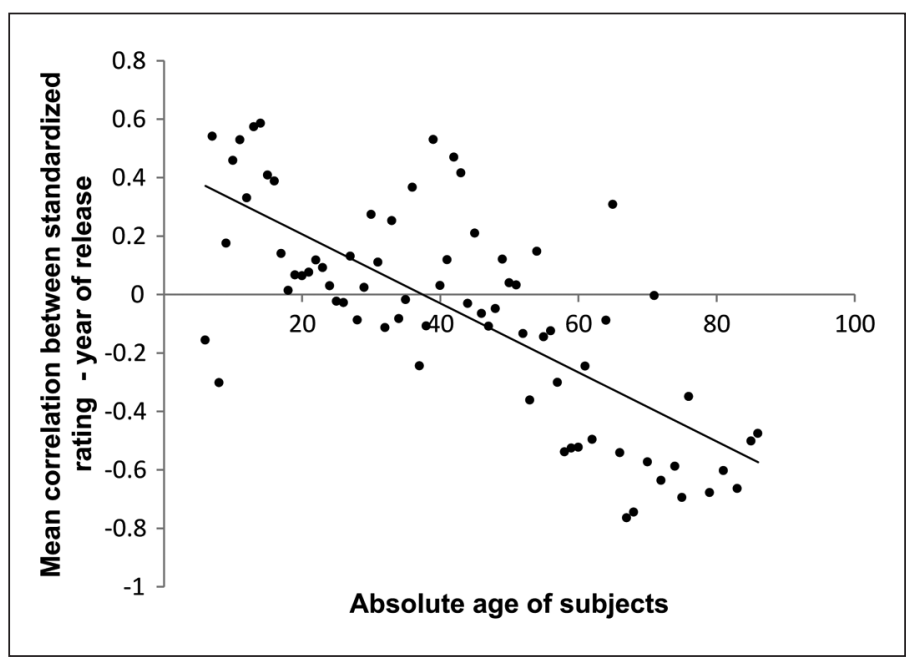

Figure 7. Average correlations of standardized ratings with year of the release of the song in relation to the absolute age of the subjects.

in Figure 8, which repeats the original plot (Figure 2) of standardized musical preference across song-specific age.

If the data of each group were looked at individually, they could readily be interpreted as the two suggested opposite types of linear relationships:

- subjects aged up to 37 years displayed a weakly increasing linear preference for newer titles (read curve from left to right)

- subjects aged above 37 years displayed a remarkably increasing linear preference for older titles (read curve from right to left)

Thus, as a speculation, the U-shaped curve seemed to emerge as an artefact of combining two types of rather linear data into one chart.

\section{Discussion}

No empirical evidence remains to sustain the overall cultural assumption that people cling to music (or even other cultural objects mentioned in the original Holbrook \& Schindler, 1989 study, p. 124) they get to know in late adolescence/early adulthood. Still, in a proper deductive fashion, this must not be considered as proof that the overall cultural assumption is incorrect. It might still be valid, since many people have experienced the suggested generation effect individually, but alternative research strategies will have to be developed to provide its empirical confirmation. While not specific to music, Holbrook and Schindler further explored the relevance of nostalgia in their later studies (Schindler \& Holbrook, 2003). The suggested relationship between individual biographies and preference for music (or other objects of culture and consumption) still appears as a valuable notion to the author.

Turning to the tables of music examples in the original (1989, p. 121) and the replication study (Table 1) finally reveals another limitation of the general design. While research on music preferences usually includes a list of 10-20 genres or styles (pop, rock, jazz, classical - to name 


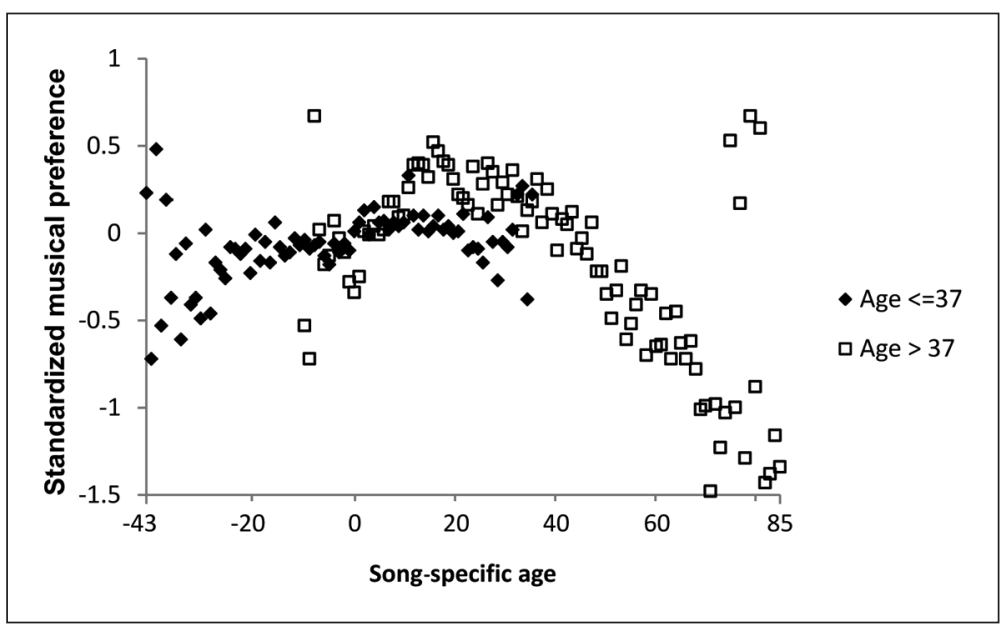

Figure 8. Formation of the inverted $U$-shaped curve as an artefact of combining two opposite, predominantly linear relationships represented in two age groups.

but a few), only middle-of-the road popular music as represented by the annual top 10 was included here. The obvious advantage of this strategy is that the year in which the subjects most likely first got to know the music can clearly be identified. On the other hand, it remains questionable if subjects ever related to the music examples used here as closely and as intensely as Frith (1987) has described for the sociology of youth. However, setting up longitudinal designs or primarily drawing on retrospective biographical data is a laborious task with limited data precision and general practicability. What we need is another clever move as inspiring as the original one from Holbrook and Schindler.

\section{Perspectives and limitations}

Showing limitations in the original study and the suggestion of a possible artefact in its main findings will of course provoke controversies. We would like to welcome all kinds of further data analysis by experts in the field beyond musicology. Suggestions include the use of lowess-curves to clearly identify artefacts and the avoidance of alpha-error accumulations. The data set of this study is available at msx.sagepub.com/supplemental.

\section{Funding}

This research received no specific grant from any funding agency in the public, commercial, or not-forprofit sectors.

\section{References}

Behne, K.-E. (1997). The development of "Musikerleben" in adolescence. How and why young people listen to music. In I. Deliège \& J. Sloboda (Eds.), Perception and cognition of music. (pp. 143-159). Hove, UK: Psychology Press.

Dunne, M. (1992). Metapop: Self-referentiality in contemporary American popular culture. Jackson, MS: University Press of Mississippi.

Frith, S. (1987). Towards an aesthetic of popular music. In R. Leppert \& S. McClary (Eds.), Music and society: The politics of composition, performance and reception. (pp. 133-149). Cambridge, UK: Cambridge University Press. 
Gembris, H. (2002). The development of musical abilities. In R. R. C. Colwell (Ed.), The new handbook of music teaching and learning. (pp. 487-508). New York, NY: Oxford University Press.

Gembris, H., \& Hemming, J. (2005). Musikalische Präferenzen. In T. Stoffer \& R. Oerter (Eds.), Spezielle Musikpsychologie (pp. 279-342). Göttingen, Germany: Hogrefe.

Goodwin, A. (1988). Sample and hold: Pop music in the digital age of reproduction. Critical Quarterly, 30(3), 34-49.

Holbrook, M. B., \& Schindler, R. M. (1989). Some exploratory findings on the development of musical tastes. Journal of Consumer Research, 16(6), 119-124.

North, A. C. (2010). Individual differences in musical taste. American Journal of Psychology, 123(2), 199-208.

Schäfer, T., \& Sedlmeier, P. (2010). What makes us like music? Determinants of music preference. Psychology of Aesthetics, Creativity and the Arts, 4(4), 223-234.

Schindler, R. M., \& Holbrook, M. (2003). Nostalgia for early experience as a determinant of consumer preferences. Psychology \& Marketing, 20(4), 275-302.

Siivola, C., Obert, M., LeBlanc, A., \& Sims, W. L. (1996). Music style preferences of different age listeners. Journal of Research in Music Education, 44(1), 49-59. 